\title{
NCOA3 is a selective co-activator of estrogen receptor a-mediated transactivation of PLAC1 in MCF-7 breast cancer cells
}

Meike Wagner ${ }^{1,2}$, Michael Koslowski ${ }^{2}$, Claudia Paret ${ }^{2}$, Marcus Schmidt ${ }^{3}$, Özlem Türeci ${ }^{4}$ and Ugur Sahin ${ }^{1,2,5^{*}}$

\begin{abstract}
Background: The placenta-specific 1 (PLAC1) gene encodes a membrane-associated protein which is selectively expressed in the placental syncytiotrophoblast and in murine fetal tissues during embryonic development. In contrast to its transcriptional repression in all other adult normal tissues, PLAC1 is frequently activated and highly expressed in a variety of human cancers, in particular breast cancer, where it associates with estrogen receptor a (ERa) positivity. In a previous study, we showed that ERa-signaling in breast cancer cells transactivates PLAC1 expression in a non-classical pathway. As the members of the p160/nuclear receptor co-activator (NCOA) family, NCOA1, NCOA2 and NCOA3 are known to be overexpressed in breast cancer and essentially involved in estrogen-mediated cancer cell proliferation we asked if these proteins are involved in the ERa-mediated transactivation of PLAC1 in breast cancer cells.
\end{abstract}

Methods: Applying quantitative real-time RT-PCR (qRT-PCR), Western Blot analysis and chromatin immunoprecipitation, we analyzed the involvement of NCOA1, NCOA2, NCOA3 in the ERa-mediated transactivation of PLAC1 in the breast cancer cell lines MCF-7 and SK-BR-3. RNAi-mediated silencing of NCOA3, qRT-PCR, Western blot analysis and ERa activation assays were used to examine the role of NCOA3 in the ERa-mediated regulation of PLAC1 in further detail. Transcript expression of NCOA3 and PLAC1 in 48 human breast cancer samples was examined by qRT-PCR and statistical analysis was performed using Student's t-test.

Results: We detected selective recruitment of NCOA3 but not NCOA1 or NCOA2 to the PLAC1 promoter only in ERa-positive MCF-7 cells but not in ERa-negative SK-BR-3 breast cancer cells. In addition, we demonstrate that silencing of NCOA3 results in a remarkable decrease of PLAC1 expression levels in MCF-7 cells which cannot be restored by treatment with estradiol $\left(E_{2}\right)$. Moreover, significant higher transcript levels of $P L A C 1$ were found only in ERa-positive human breast cancer samples which also show a NCOA3 overexpression.

Conclusions: In this study, we identified NCOA3 as a selective co-activator of ERa-mediated transactivation of PLACI in MCF-7 breast cancer cells. Our data introduce PLAC1 as novel target gene of NCOA3 in breast cancer, supporting the important role of both factors in breast cancer biology.

Keywords: NCOA3, PLAC1, Estrogen-signaling, Breast cancer, Estrogen receptor a, Tumor antigen

\footnotetext{
* Correspondence: ugur.sahin@tron-mainz.de

'Department of Internal Medicine III, Division of Translational and

Experimental Oncology, University Medical Center, Johannes Gutenberg

University, 55131 Mainz, Germany

${ }^{2}$ TRON-Translational Oncology gGmbH at the University Medical Center of

the Johannes Gutenberg University, 55131 Mainz, Germany

Full list of author information is available at the end of the article
} 


\section{Background}

Recently, we introduced PLAC1 (placenta-specific 1) as a novel member of cancer-associated placental genes [1] The PLAC1 gene encodes a membrane-associated protein which is speculated to have a receptor-like function modulating specific cell-cell or ligand-receptor interactions unique to the maternal-placental interface $[2,3]$. Indeed, Jackman and coworkers recently disclosed Plac1 as an essential factor for normal placental and embryonic development using a Plac1 mutant mouse model [4]. In murine fetal tissues, Plac1 is expressed in several tissues, including brain, heart, kidney, liver, lung and intestine. Plac1 knockout mice have an increased risk to develop a lethal hydrocephalus indicating that Plac1 plays a major role in brain development [5]. In adult normal tissues, expression of PLAC1 is strictly confined to differentiated cells of the placental syncytiotrophoblast, in which it is expressed throughout human gestation. In all other adult normal tissues, in contrast, PLAC1 underlies tight transcriptional repression. In a variety of human cancers, in particular breast cancer, PLAC1 is frequently activated and highly expressed [1]. Moreover, we found previously that PLAC1 is a critical factor for cancer cell proliferation, as silencing of PLAC1 results in a pronounced G1 cell cycle arrest accompanied by decreased cyclin D1 expression and hypophosphorylation of AKT kinase. Tumorpromoting functions of PLAC1 can be antagonized by specific antibodies, thereby qualifying PLAC1 as promising candidate for targeted therapies of cancer.

The expression of PLAC1 is regulated by two distinct promoters, P1 and P2, separated by $105 \mathrm{~kb}$. In human placenta and the human breast cancer cell line MCF-7, $\mathrm{P} 2$ is the preferred promoter, whereas P1 is preferentially used in the human choriocarcinoma cell lines BeWo and JAR [6]. By analysis of the promoter P2, we previously discovered in three different breast cancer cell lines that basal expression of PLAC1 is governed by the concerted action of the transcription factors SP1 and isoform 2 of CCAAT/enhancer binding protein $\beta(\mathrm{C} / \mathrm{EBP} \beta)$ that is selectively expressed in placental tissue and breast cancer cells [7]. Moreover, we showed that ER $\alpha$-signaling in MCF-7 cells further transactivates PLAC1 expression in a non-classical pathway that does not depend on the presence of estrogen-response elements (ERE), but rather by directly tethering activated ER $\alpha$ to DNA-bound SP1 and $\mathrm{C} / \mathrm{EBP} \beta-2$. Accordingly, ER $\alpha$-positive tumors display significantly higher PLAC1 expression levels compared with ER $\alpha$-negative tumors [7].

Gene regulation by ER $\alpha$ requires the recruitment of a multitude of transcriptional co-regulators to the promoters of estrogen-responsive genes. Through interaction with these co-activator proteins, the activated receptor directs the assembly and stabilization of a pre-initiation complex that ultimately conducts the transcription of target genes.
A key family of co-activators involved in the regulation of steroid receptor-mediated transcription is the p160/NCOA family [8], consisting of three members: nuclear receptor co-activator 1 (NCOA1) [9], NCOA2 [10] and NCOA3 [11], also known as steroid receptor co-activator 3 (SRC-3) and amplified in breast cancer 1 (AIB1) [12]. Gene amplification and overexpression of NCOA1, NCOA2 and NCOA3 in breast cancer has been described previously by several groups thus contributing to the development of cancer [8,12-21].

The prominent expression and function of PLAC1 particularly in breast cancer led our attention to this coactivator family. In the present study, we examined the involvement of p160/NCOA family members in the regulation of PLAC1 in ER $\alpha$-positive and -negative breast cancer cells and identified NCOA3 as a selective co-activator of ER $\alpha$-mediated transactivation of PLAC1 in ER $\alpha$-positive MCF-7 breast cancer cells.

\section{Methods}

\section{Tissues, cell lines and culture conditions}

Breast cancer tissues were obtained as human surplus materials during routine diagnostic or therapeutic procedures and were stored at $-80^{\circ} \mathrm{C}$ until use. The study was approved by the ethical review board of the medical association of Rhineland-Palatinate. Informed consent has been obtained and all clinical investigation has been conducted according to the principles expressed in the Declaration of Helsinki. Breast cancer cell lines SK-BR-3 and MCF-7 were obtained from American Type Culture Collection (ATCC) and cultured in Dulbecco's modified Eagle's medium (DMEM), 10\% fetal calf serum (FCS). Prior to estradiol-treatment studies, MCF-7 cells were cultured in phenol-red free medium supplemented with 10\% charcoal stripped FCS for $72 \mathrm{~h}$. Cells were treated with $100 \mathrm{nM}$ 17- $\beta$-estradiol $\left(\mathrm{E}_{2}\right)$ (Sigma Aldrich) and/or with $5 \mu \mathrm{M}$ of the complete estrogen receptor blocker ICI 182,780 (ICI) (Sigma Aldrich) for $12 \mathrm{~h}$.

\section{Small interfering RNA duplexes and transfection}

A pool of four different siRNA duplexes (Dharmacon) targeting NCOA3 mRNA sequence (NM_006534) (siRNA 1 target sequence $5^{\prime}$-CAC AAU ACC UGC AAU AUA A3', siRNA 2 target sequence 5'-GAA AGG UUG UCA AUA UAG A-3', siRNA 3 target sequence 5'-GAA GGU GUA UUC AGA GAU U-3', siRNA 4 target sequence 5' CGG AAA CAU UGU AUU UGU A-3') or a mixture of two different siRNA duplexes (Qiagen) targeting PLAC1 mRNA sequence (NM_021796) (siRNA 1 targeting nucleotides 342 to 362 ; target sequence 5 '-CUC CAU GAG AGU AGC CAG CAA-3' and siRNA 2 targeting nucleotides 670 to 690; target sequence $5^{\prime}$-CCG GUU CAG GAC AAA GTC CAA-3') was used. As a control, a pool of four non-silencing (ns) siRNA duplexes (D-001810-10- 
05; Dharmacon) was used. MCF-7 cells were transfected with $5 \mathrm{nM}$ siRNA duplexes using HiPerFect transfection reagent (Qiagen) and SK-BR-3 cells with $100 \mathrm{nM}$ siRNA duplexes using DharmaFect 1 (Dharmacon) according to the respective manufacturer's protocol. $48 \mathrm{~h}$ after transfection, cells were harvested for isolation of total RNA, subsequent cDNA synthesis and quantitative realtime RT-PCR or whole cells were lysed for western blot analysis.

\section{RNA-isolation, first-strand cDNA synthesis and quantitative real-time RT-PCR}

Total RNA from cells or tissues was isolated using RNeasy Mini Kit (Qiagen) and subsequent conversion to cDNA was conducted using SuperScript II Kit (Invitrogen) according to the manufacturer's instructions. Quantitative realtime RT-PCR was performed using the ABI PRISM 7300 sequence detection system and software (Applied Biosystems with QuantiTect SYBR green Kit (Qiagen)). The reactions were performed in duplicates in a 40 cycle PCR. After normalization to the housekeeping gene HPRT1 (sense 5'TGA CAC TGG CAA AAC AAT GCA-3'; antisense 5'GGT CCT TTT CAC CAG CAA GCT-3'; 62 ${ }^{\circ} \mathrm{C}$ annealing) the relative expression of $N C O A 1$ (sense $5^{\prime}$-GGC ATC AAT ATG AGA TCA GGC ATG-3'; antisense 5' 'TTC CTA TCG CTC CTT GCT GCC A-3'; $62^{\circ} \mathrm{C}$ annealing), NCOA2 (sense 5' -CTG GAG TAC CAA CAC AGG CAC3'; antisense 5'-CTG TGC ATT TGC CTG GGG AAT CC-3'; $62^{\circ} \mathrm{C}$ annealing), NCOA3 (sense 5'-GAA AGA GCA TTA TTG GAC CAG C-3'; antisense 5'-TGT CCC TGA AGA TGA AAG CC-3'; $60^{\circ} \mathrm{C}$ annealing) and PLAC1 (sense 5'-AAA TTT GGC AGC TGC CTT CAC-3'; antisense $5^{\prime}$-TGA TGC CAC ATT CAG TAA CAC-3'; 60 annealing) was quantified using $\Delta \Delta \mathrm{Ct}$ calculation. A calibrator of 16 corresponding to 40 (maximal number of cycles used in the PCR) minus the mean of the HPRT1 values of the breast cancer tissue samples was used in this analysis.

\section{Western blot analysis}

Whole cell lysates were prepared in 4X Laemmli sample buffer (250 mM Tris $\mathrm{HCl}, 34 \%$ glycerol, 8.2\% SDS, $0.008 \%$ bromphenol blue) and supplemented with $5 \% \beta$ mercaptoethanol. Extracts were subjected to SDS-PAGE and subsequently blotted onto nitrocellulose membrane (Whatman). Immunostaining was performed using mouse or rabbit monoclonal antibodies reactive against NCOA1 (128E7; Cell Signaling), NCOA3 (5E11; Cell Signaling), PLAC1 (22-3A-1; Ganymed Pharmaceuticals) and $\beta$-actin (AC-15, Sigma Aldrich) or using a polyclonal rabbit antibody reactive to NCOA2 (ab10491, Abcam). Detection of primary antibodies was performed with horseradish peroxidase-conjugated goat-anti-mouse or goat-anti-rabbit secondary antibodies (Jackson ImmunoReseach Laboratories). $\beta$-actin was used as a loading control.

\section{Chromatin immunoprecipitation (ChIP)}

ChIP assays of MCF-7 and SK-BR-3 nuclear cell extracts were performed as previously described [7]. In short, ChIP was performed with chromatin prepared from MCF-7 or SK-BR-3 cells, which were either untreated or treated with $17-\beta$-estradiol $\left(\mathrm{E}_{2}\right)$. As additional controls, cells treated concomitantly with $17-\beta$-estradiol and the estrogen receptor blocker ICI 182,780 or this compound alone were included. The purified DNA was analyzed by conventional PCR and quantitative real time PCR for the presence of the human PLAC1 promoter fragment -348/198 bp containing the $C / E B P \beta$ and SP1 elements (sense 5'-CAA CAG CAA GCA CTA CAA GTG-3'; antisense 5'-GAA GCT CAA CTC GGT GCA CTT GTT C-3') and for a fragment $-1219 /-1064$ bp upstream of the promoter as negative control (sense $5^{\prime}$-AAG CAC TTA GGA CAG CAT CTG-3'; antisense 5'-TGA ATG ATA CCT ACT GTC ATG) following immunoprecipitation with antibodies reactive to SP1 (ab13370), C/EBP $\beta-2$ (ab32358), ER $\alpha$ (ab2746), NCOA1 (ab84), NCOA2 (ab9261), NCOA3 (ab2782), p300 (ab14984), pCAF (ab12188), АcH3 (ab12179), AcH4 (ab15823), TFIIB (ab12094) and RNAPolymerase II (ab5131) (all from Abcam).

\section{Statistical analysis}

Two-tailed Student's $t$-test was used to analyze statistical significance of NCOA3 compared to NCOA1 and NCOA2 transcript expression in MCF-7 and SK-BR-3 cells and PLAC1 transcript expression in human breast cancer samples. $P$-values $\leq 0.05\left(^{*}\right)$ were considered statistically significant.

\section{Results}

In a first experiment, we analyzed expression of NCOA1, NCOA2 and NCOA3 in ER $\alpha$-positive MCF-7 and ER $\alpha$ negative SK-BR-3 breast cancer cells that both have been shown to express PLAC1 protein [1,7]. Expression of all three co-activators could be confirmed in both cell lines on transcript level by quantitative real-time RT-PCR and on protein level by Western blot analysis (Figure 1A, 1B). We found significantly higher expression of NCOA3 compared to NCOA1 and NCOA2 in MCF-7 cells, whereas in SK-BR-3 cells expression of NCOA3 was slightly reduced compared to the other family members.

Next, we sought to determine if members of the p160/ NCOA family participate in the formation of an estradiol $\left(E_{2}\right)$-dependent pre-initiation complex on the endogenous PLAC1 promoter. Chromatin immunoprecipitation (ChIP) assays were performed with nuclear extracts from untreated MCF-7 and SK-BR-3 cells or cells treated with $100 \mathrm{nM} \mathrm{E} \mathrm{E}_{2}$ in presence or absence of the ER-antagonist 

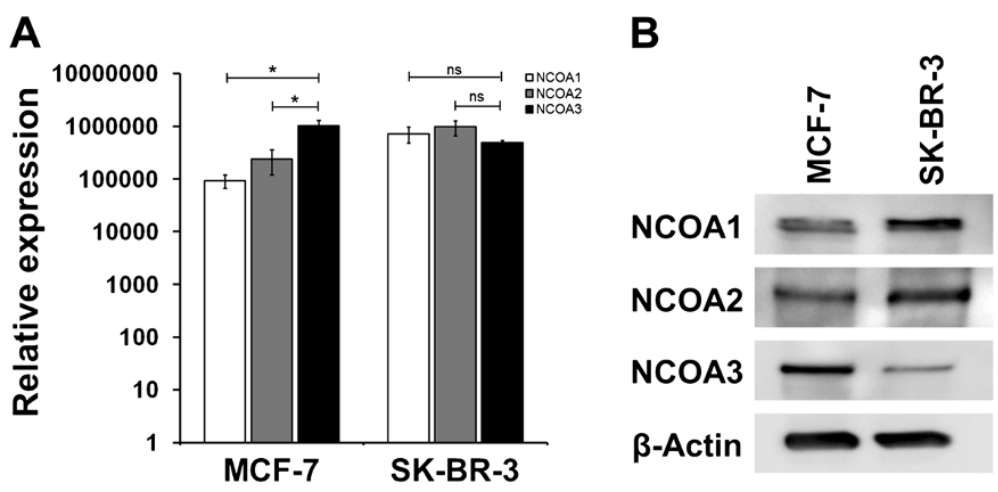

Figure 1 Expression of NCOA1, 2 and 3 in ERa-positive MCF-7 and ERa-negative SK-BR-3 breast cancer cells. (A) Real-time RT-PCR quantification of NCOA1, 2 and 3 mRNA expression in MCF-7 and SK-BR-3 breast cancer cells. Shown are mean and standard deviation of three individual experiments. Statistical analysis of NCOA3 mRNA expression compared to NCOA1 and 2 were performed using two-tailed Student's $t$-test. P-values $\leq 0.05\left(^{*}\right)$ were considered statistically significant. (B) Protein expression of NCOA1, 2 and 3 in MCF-7 and SK-BR-3 breast cancer cells was analyzed by Western blot. $\beta$-actin was used as a loading control.

ICI 182,780 (ICI), which is known to efficiently inhibit the actions of endogenous and exogenous $E_{2}$, or with ICI alone. We could confirm our recent data [7], showing that recruitment of $\mathrm{C} / \mathrm{EBP} \beta-2$ and $\mathrm{ER} \alpha$ to the PLAC1 promoter was strongly and specifically induced by $E_{2}$ in MCF-7 cells, whereas no apparent differences in the recruitment of SP1 in the presence or absence of $E_{2}$ was observed (Figure 2A, 2B). Interestingly, we now detected recruitment of NCOA3, but not NCOA1 and NCOA2 to the complex by $\mathrm{E}_{2} / \mathrm{ER} \alpha$.

Full NCOA3 co-activator function also requires the recruitment of the histone acetyl transferases p300 and pCAF. Acetylation of histones by these factors modifies chromatin structure and provides a more accessible promoter environment for recruitment of components of the general transcriptional machinery [22]. Accordingly, we found specific recruitment of histone acetyl transferases p300 and pCAF, acetylated histones $\mathrm{H} 3$ and $\mathrm{H} 4$, as well as general transcription factor IIB (TFIIB) and RNA polymerase II (Pol II) to the PLAC1 gene promoter upon $\mathrm{E}_{2}$-treatment. In contrast, in ER $\alpha$-negative SK-BR-3 cells, formation of this pre-initiation complex by treatment with $E_{2}$ could not be observed. These results indicate a selective involvement of NCOA3 in the assembly of an active $E_{2} / E R \alpha$-induced pre-initiation complex on the PLAC1 promoter.

To directly assess the impact of NCOA3 on PLAC1 transcript and protein expression, we silenced $\mathrm{NCOA3}$ in MCF-7 and SK-BR-3 cells by transient transfection with specific siRNA duplexes. Transcript levels of NCOA3 were specifically reduced by $80 \%$ compared to nontransfected cells and cells transfected with non-silencing control siRNA duplexes in both cell lines (Figure 3A). Strikingly, silencing of $N C O A 3$ resulted in a concomitant loss of PLAC1 expression only in ER $\alpha$-positive MCF-7 cells but not in ER $\alpha$-negative SK-BR-3 cells. These findings could be confirmed on protein level by Western blot analysis (Figure 3B). Noteworthy, silencing of $N C O A 3$ in MCF-7 cells did not result in complete loss of PLAC1 expression, as basal expression of PLAC1 in breast cancer is not dependent on ER $\alpha$-signaling but rather on the presence of SP1 and C/EBP $\beta-2$ [7]. The importance of NCOA3 for $\mathrm{E}_{2}$-mediated transactivation of PLAC1 was further verified in $\mathrm{E}_{2}$-depleted MCF-7 cells transfected with siRNA duplexes (Figure 3C). Exposure of these cells to $100 \mathrm{nM} \mathrm{E}_{2}$ induced PLAC1 expression only in non-transfected cells and cells transfected with non-silencing siRNA duplexes. In contrast, PLAC1 transactivation was nearly abolished in cells lacking NCOA3, further confirming the important function of NCOA3 for $\mathrm{E}_{2} / \mathrm{ER} \alpha$-induced transactivation of PLAC1 in breast cancer cells.

To consolidate our data in vivo, we analyzed expression of PLAC1 and NCOA3 transcripts in 48 human primary breast cancer tissue samples. Since overexpression of NCOA3 in breast cancer has been shown to be associated with clinical parameters [14,23], we were interested if high PLAC1 expression is associated with $N C O A 3$ overexpression. Therefore, we subdivided the 48 breast cancer samples into two groups depending on $N C O A 3$ expression levels. Relative expression of NCOA3 below 100000 (in contrast, relative expression of $N C O A 3$ in normal breast tissue is about 10000 , data not shown) were considered to be ' $N C O A 3$ low' $(\mathrm{N}=25)$, whereas relative expression of NCOA3 over 100000 were considered to be 'NCOA3 high' $(\mathrm{N}=23)$. While no difference in PLAC1 expression was found between $N C O A 3$ low and NCOA3 high expressing breast cancer tissues regardless of the ER-status or in the ER $\alpha$-negative samples, a significant higher 


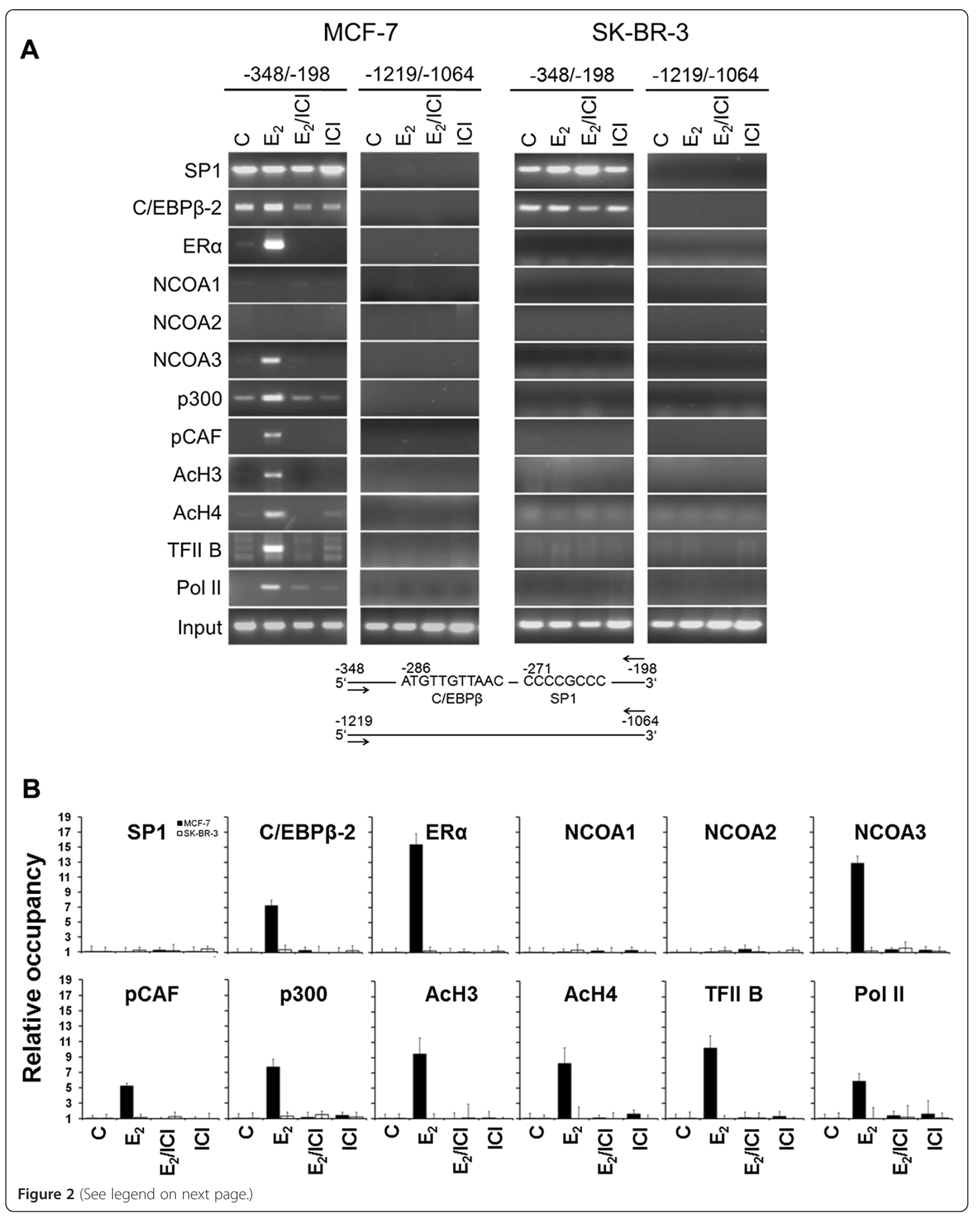


(See figure on previous page.)

Figure 2 Selective $E_{2}$-dependent recruitment of NCOA3 to the endogenous PLAC1 promoter in ERa positive MCF-7 cells. (A) Chromatin immunoprecipitation (ChIP) was performed with chromatin prepared from MCF-7 and SK-BR-3 cells which were either untreated (C), treated with 17- $\beta$-estradiol $\left(E_{2}\right)$ alone, with $I C l$ alone or with both compounds $\left(E_{2} / I C I\right)$. The promoter region of PLACl containing the C/EBP $\beta$ and SP1 elements $(-348 /-198)$ and a region upstream of the promoter $(-1219 /-1064)$ as negative control were analyzed by PCR following immunoprecipitation with the indicated antibodies. Amplification products from soluble chromatin prior to precipitation are shown as control (Input). (B) Quantitative analysis of the recruitment and occupancy shown in (A) determined by real-time RT-PCR. The results corrected by input are shown as fold increase compared to unstimulated cells used as a reference.
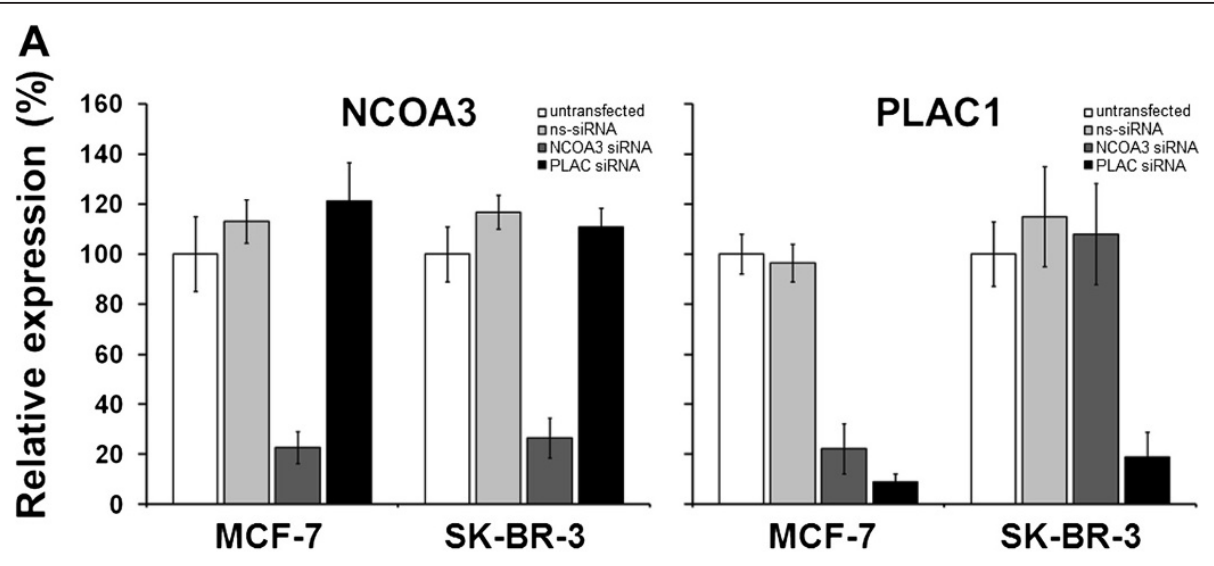

B

MCF-7

SK-BR-3
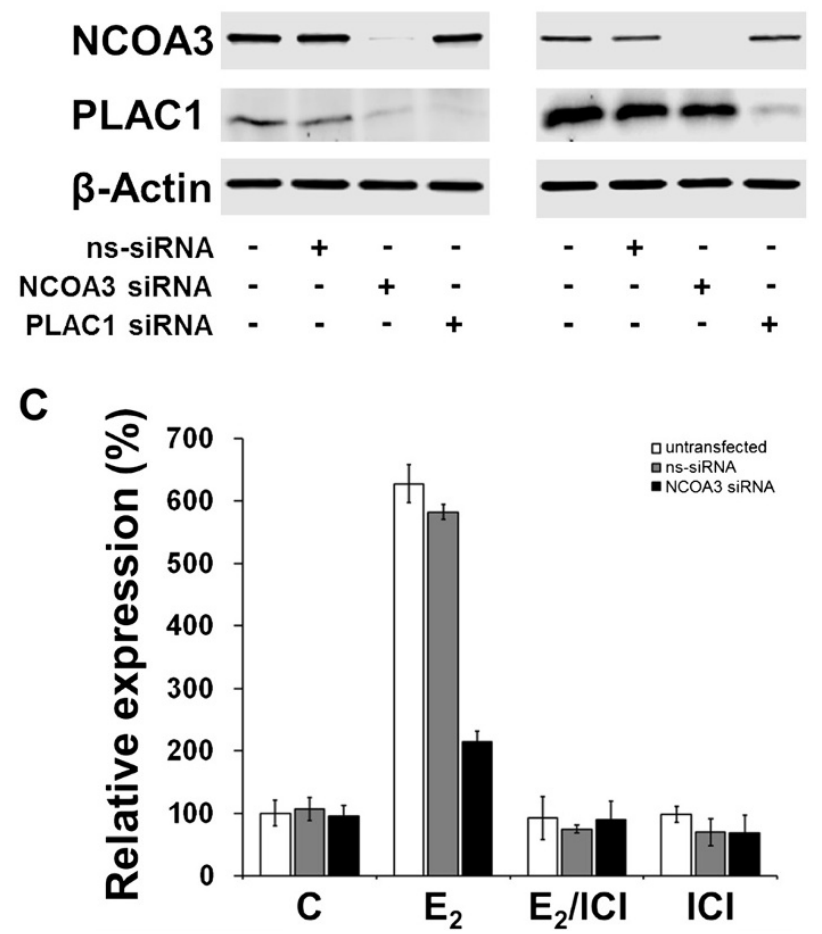

Figure 3 ERa-mediated transactivation of PLAC1 is dependent on NCOA3. (A) Quantitative real-time RT-PCR expression analysis of NCOA3 and PLAC1 in MCF-7 and SK-BR-3 cells $48 \mathrm{~h}$ after transfection with NCOA3- or PLAC1-specific siRNA duplexes. ns-siRNA, non-silencing siRNA. The results are shown as fold increase compared to untransfected cells used as a reference. (B) Protein expression of NCOA3 in MCF-7 and SK-BR3 cells $48 \mathrm{~h}$ after transfection with siRNA duplexes targeting NCOA3 or PLAC1 mRNA. Transfection of cells with PLAC1-specific siRNA was conducted to verify that knockdown of NCOA3 specifically affects PLAC1 mRNA and protein level. (C) Quantitative real-time RT-PCR analysis of PLAC1 expression in $E_{2}$-depleted (72 h) MCF-7 cells in response to treatment with $100 \mathrm{nM} \mathrm{E} \mathrm{E}_{2}$, no $E_{2}(C)$, or $E_{2}$ and $5 \mu \mathrm{M} \mathrm{ICl} \mathrm{(E2/ICl),} \mathrm{or} \mathrm{ICl} \mathrm{alone} \mathrm{for} 12 \mathrm{~h}$. $48 \mathrm{~h}$ prior to treatment, cells were transfected with siRNA duplexes targeting NCOA3. Shown are mean and standard deviation of two independent experiments. 
expression of PLAC1 in the NCOA3 high expressing breast cancer samples was detected exclusively in ER $\alpha$ positive breast cancer samples (Figure 4).

\section{Discussion}

In this study, we have characterized the role of the p160/ NCOA family of co-activators in the regulation of PLAC1 in breast cancer cells. Our data show that NCOA3 but not NCOA1 or NCOA2 is selectively recruited to the PLAC1 promoter upon $\mathrm{E}_{2}$-treatment. Silencing of $\mathrm{NCOA3}$ results in loss of PLAC1 transactivation after $\mathrm{E}_{2}$-stimulation only in ER $\alpha$-positive MCF-7 but not in ER $\alpha$-negative SK-BR-3 breast cancer cells. Moreover, we observed a significant correlation of PLAC1 expression and NCOA3 overexpression in a cohort of ER $\alpha$-positive breast cancer patients.

The members of the p160/NCOA family of co-activators function in a similar fashion to stimulate the transcription of nuclear receptor target genes. However, despite their significant homology in structure and sequence NCOA1, NCOA2 and NCOA3 exhibit unique, non-redundant functions in different cell types and tissues $[8,21,24]$. In human breast cancer, NCOA3 is amplified and overexpressed at transcript and protein level in a significant portion of tumors $[12,20,25]$ and its particular relevance is underlined from the induction of spontaneous mammary tumors in mice overexpressing NCOA3 in mammary epithelial cells [26]. This is supported by studies showing that NCOA3 can stimulate the growth of breast cancer cell lines through estrogen-independent and estrogen-dependent mechanisms. In fact, NCOA3 promotes the transcriptional activity of several transcription factors, including E2F-1, RAR, NFKB, and STAT6 [27-30].

In ER-positive breast cancers, NCOA3 is required for maximal activity of ER $\alpha$ and other hormone receptors [31,32]. Changes in NCOA3 expression influence ER $\alpha$ dependent gene expression and consequently modulate cellular processes that promote cancer such as proliferation, invasion and cell motility [33,34]. Indeed, depletion of NCOA3 protein in MCF-7 cells results in decreased $\mathrm{E}_{2}$-stimulated proliferation in vitro and a decreased growth of MCF-7 cells in xenografts in mice. This function of NCOA3 is mediated through downstream effectors like cyclin D1, which plays a pivotal role in estrogen-dependent proliferation [35]. Interestingly, we found previously that PLAC1 is a critical factor for breast cancer progression, as RNAi-mediated silencing of PLAC1 in MCF-7 and BT-549 breast cancer cells results in decreased cyclin D1 levels and induces a G1-S cell cycle block with nearly complete abrogation of proliferation [1]. Thus our data introduce PLAC1 as a possible downstream effector of NCOA3 mediated actions in ER $\alpha$-positive breast cancer cells. However, further experiments are required to also show a functional correlation between $\mathrm{E}_{2}$-induced breast cancer cell proliferation and PLAC1 expression.

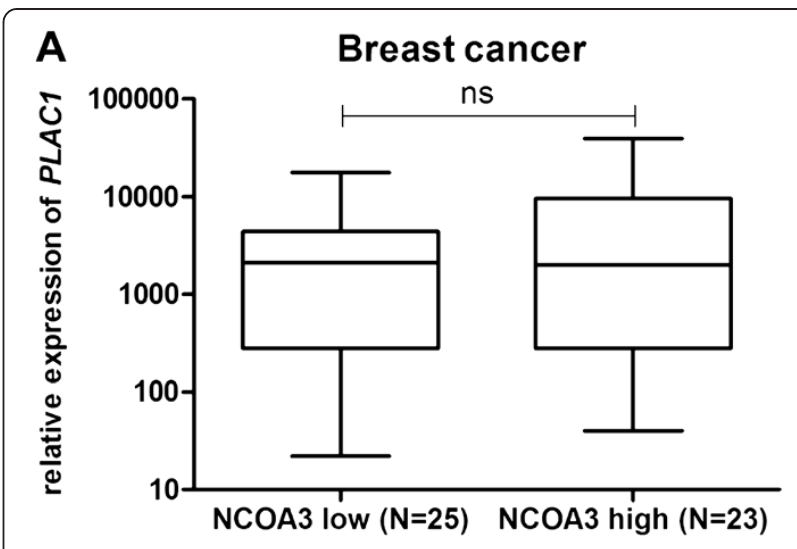

B ER $\alpha$-positive breast cancer

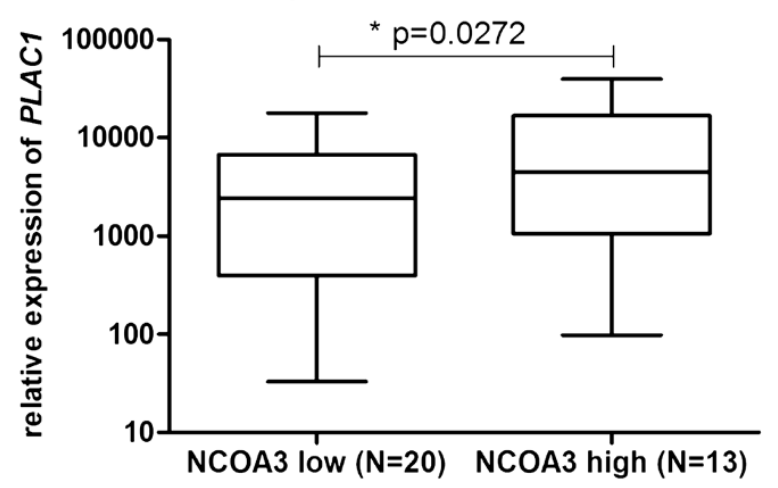

C ER $\alpha$-negative breast cancer

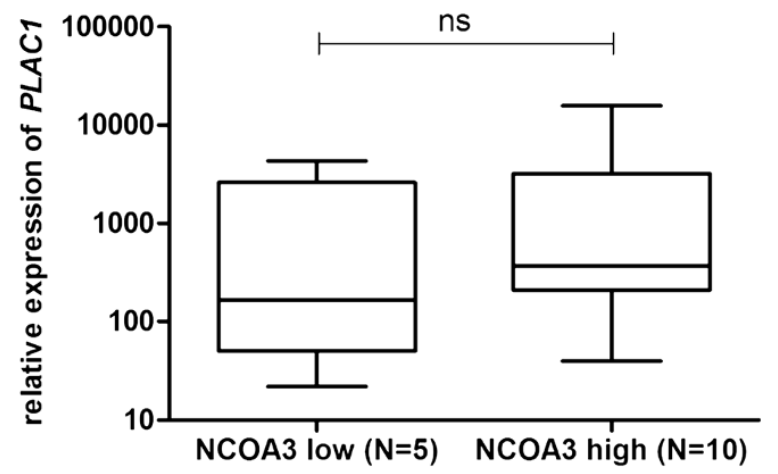

Figure 4 mRNA expression of PLAC1 is elevated in NCOA3 overexpressing and ERa-positive human breast cancer samples. (A) NCOA3 and PLAC1 mRNA expression was examined by quantitative real-time RT-PCR in 48 human breast cancer samples. Relative expression of NCOA3 below 100000 were considered to be 'NCOA3 low' ( $N=25)$, whereas relative expression of NCOA3 over 100 000 were considered to be 'NCOA3 high' $(\mathrm{N}=23)$. (B) Evaluation of PLAC1 expression in ERa-positive breast cancer samples with 'NCOA3 low' ( $N=20)$ or 'NCOA3 high' ( $N=13)$ status. (C) Evaluation of PLAC1 expression in ERa-negative breast cancer samples with 'NCOA3 low' $(\mathrm{N}=5)$ or 'NCOA3 high' $(\mathrm{N}=10)$ status. Statistical analysis was performed using two-tailed Student's $t$-test. $P \leq 0.05\left(^{*}\right)$ was considered statistically significant. 
Noteworthy, NCOA3 overexpression in breast cancer correlates with larger tumor size, higher tumor grade, as well as with the expression of ERBB2 [8]. Furthermore, high levels of NCOA3 are associated with resistance to therapy and a shorter disease free survival in patients with ER $\alpha$ positive tumors treated with the selective ER-modulator Tamoxifen. Based on these observations NCOA3 has been under investigation as a target for treatment of breast cancer [36]. Since we detect a significant correlation between NCOA3 overexpression and PLAC1 expression in ER $\alpha-$ positive breast cancer patients this adds to the relevance of understanding the role of PLAC1 in the NCOA3/ER $\alpha$-signaling pathway and might open new therapeutic concepts for breast cancer.

The complex expression pattern of PLAC1 in placenta and cancer is regulated by two distinct promoters. In this study, we demonstrate explicit involvement of NCOA3 in the formation of an $\mathrm{E}_{2}$-dependent pre-initiation complex at the PLAC1 P2 promoter. The P2 promoter transcript predominates in placenta and MCF-7 breast cancer cells. However, both promoters are active to some extent in placenta as well several other cancer-derived cell lines and can be both activated by retinoid X receptor alpha (RXR $\alpha)$ in conjunction with liver $\mathrm{X}$ receptor alpha (LXR) [6]. $\mathrm{RXR} \alpha$ functions as homodimers or as heterodimers with other nuclear receptors including peroxisome proliferatoractivated receptor (PPAR) isoforms [23]. Indeed, it was shown that activation of PPAR $\delta$ in the mouse mammary epithelium results in the appearance of estrogen receptorand progesterone receptor-positive and ErbB2-negative infiltrating ductal carcinomas which are associated with an up-regulation of Plac1 [37]. This suggests a function of PPAR $\delta$ in the regulation of Plac1 but remains to be proven.

Furthermore, very recently, involvement of TP53, RB and NCOA2 in regulation of PLAC1 at promoter P1 was demonstrated in SV40 transduced primary fibroblasts. While expression of TP53 represses PLAC1 promoter P1, RB potentiated PLAC1 transcription in conjunction with NCOA2, particularly when RXR $\alpha$ and LXR agonists were present [38]. These results suggest that NCOA2 and NCOA3 act under different circumstances as activators of PLAC1 from promoter $\mathrm{P} 1$ or $\mathrm{P} 2$ respectively. In which extend NCOA3 can act at the promoter P1 for example in placenta remains to be analyzed. Intriguingly, NCOA3 can act as a co-activator also of PPARs [23] and was found to inhibit TP53 in breast cancer cells [39] implicating a broader involvement of NCOA3 in regulation of PLAC1. Thus, additional studies are required to dissect the complex regulation of PLAC1 in placenta and cancer tissues.

\section{Conclusions}

In conclusion, our results shed further light on the composition of the $\mathrm{E}_{2} / \mathrm{ER} \alpha$-mediated transactivation complex at the PLAC1 promoter in breast cancer cells. Our results show that NCOA3 is necessary for $\mathrm{E}_{2}$-dependent transactivation of PLAC1 in an ER $\alpha$-dependent manner. Moreover, we demonstrate a relevant correlation of PLAC1 expression and $N C O A 3$ overexpression in human breast cancer tissues restricted to the ER $\alpha$-positive samples. Our findings provide the basis to further dissect the role of PLAC1 in the ER $\alpha$-signaling pathway in breast cancer and suggest PLAC1 as a novel target gene of NCOA3 in ER $\alpha$ positive MCF-7 breast cancer cells supporting the role of both factors in breast cancer biology. The functional relationship between PLAC1 and NCOA3 as well as the correlation analysis of $P L A C 1$ expression with various clinical parameters like tumor size, overall and disease-free survival as well as resistance to therapy will be subjects of further studies.

\section{Competing interests}

US, ÖT and MK are holding patent applications on PLAC1 as therapeutic target for antibody-based cancer immunotherapy. ÖT is CEO/CSO of Ganymed Pharmaceuticals AG. US is managing director (science and research) of TRON and founder of BioNTech AG. MW, CP and MS declare that they have no competing interests.

\section{Authors' contributions}

MW and MK carried out the experiments. MW, MK, CP and US designed the study. MW, MK and CP wrote the manuscript. MS provided the breast cancer tissues. ÖT provided the anti-PLAC1 antibody. ÖT and US contributed to the manuscript draft. All authors have read and approved the final manuscript.

\section{Acknowledgements}

The authors would like to thank Sabine Häcker, Christoph Kneip and John C. Castle for carefully proof-reading the manuscript.

\section{Author details}

${ }^{1}$ Department of Internal Medicine III, Division of Translational and Experimental Oncology, University Medical Center, Johannes Gutenberg University, 55131 Mainz, Germany. ${ }^{2}$ TRON-Translational Oncology gGmbH at the University Medical Center of the Johannes Gutenberg University, 55131 Mainz, Germany. ${ }^{3}$ Department of Gynecology and Obstetrics, University Medical Center, Johannes Gutenberg University, 55131 Mainz, Germany. ${ }^{4}$ Ganymed Pharmaceuticals AG, 55131 Mainz, Germany. ${ }^{5}$ BioNTech AG, 55131 Mainz, Germany.

Received: 23 August 2013 Accepted: 28 November 2013

Published: 4 December 2013

\section{References}

1. Koslowski M, Sahin U, Mitnacht-Kraus R, Seitz G, Huber C, Tureci O: A placenta-specific gene ectopically activated in many human cancers is essentially involved in malignant cell processes. Cancer Res 2007, 67:9528-9534

2. Cocchia M, Huber R, Pantano S, Chen EY, Ma P, Forabosco A, Ko MS, Schlessinger D: PLAC1, an Xq26 gene with placenta-specific expression. Genomics 2000, 68:305-312.

3. Fant M, Weisoly DL, Cocchia M, Huber R, Khan S, Lunt T, Schlessinger D: PLAC1, a trophoblast-specific gene, is expressed throughout pregnancy in the human placenta and modulated by keratinocyte growth factor. Mol Reprod Dev 2002, 63:430-436.

4. Jackman SM, Kong XY, Fant ME: Plac1 (placenta-specific 1) is essential for normal placental and embryonic development. Mol Reprod Dev 2012, 79:564-572.

5. Kong X, Jackman SM, Fant ME: Plac1 (placenta-specific 1) is widely expressed during fetal development and is associated with a lethal form of hydrocephalus. Birth Defects Res A Clin Mol Teratol 2013, 97:571-577. 
6. Chen $Y$, Moradin A, Schlessinger D, Nagaraja R: RXRalpha and LXR activate two promoters in placenta- and tumor-specific expression of PLAC1. Placenta 2011, 32:877-884.

7. Koslowski M, Tureci O, Biesterfeld S, Seitz G, Huber C, Sahin U: Selective activation of trophoblast-specific PLAC1 in breast cancer by CCAAT/enhancer-binding protein beta (C/EBPbeta) isoform 2. J Biol Chem 2009, 284:28607-28615.

8. Xu J, Wu RC, O'Malley BW: Normal and cancer-related functions of the p160 steroid receptor co-activator (SRC) family. Nat Rev Cancer 2009, 9:615-630.

9. Onate SA, Tsai SY, Tsai MJ, O'Malley BW: Sequence and characterization of a coactivator for the steroid hormone receptor superfamily. Science 1995, 270:1354-1357.

10. Voegel JJ, Heine MJ, Zechel C, Chambon P, Gronemeyer H: TIF2, a 160 kDa transcriptional mediator for the ligand-dependent activation function AF-2 of nuclear receptors. EMBO J 1996, 15:3667-3675.

11. Torchia J, Rose DW, Inostroza J, Kamei Y, Westin S, Glass CK, Rosenfeld MG: The transcriptional co-activator $\mathrm{p} / \mathrm{CIP}$ binds CBP and mediates nuclearreceptor function. Nature 1997, 387:677-684.

12. Anzick SL, Kononen J, Walker RL, Azorsa DO, Tanner MM, Guan XY, Sauter G, Kallioniemi OP, Trent JM, Meltzer PS: AIB1, a steroid receptor coactivator amplified in breast and ovarian cancer. Science 1997, 277:965-968.

13. Bautista S, Valles H, Walker RL, Anzick S, Zeillinger R, Meltzer P, Theillet C: In breast cancer, amplification of the steroid receptor coactivator gene AIB1 is correlated with estrogen and progesterone receptor positivity. Clin Cancer Res 1998, 4:2925-2929.

14. Bouras T, Southey MC, Venter DJ: Overexpression of the steroid receptor coactivator AIB1 in breast cancer correlates with the absence of estrogen and progesterone receptors and positivity for p53 and HER2/ neu. Cancer Res 2001, 61:903-907.

15. Fleming FJ, Hill AD, McDermott EW, O'Higgins NJ, Young LS: Differential recruitment of coregulator proteins steroid receptor coactivator-1 and silencing mediator for retinoid and thyroid receptors to the estrogen receptor-estrogen response element by beta-estradiol and 4hydroxytamoxifen in human breast cancer. J Clin Endocrinol Metab 2004, 89:375-383.

16. Fleming FJ, Myers E, Kelly G, Crotty TB, McDermott EW, O'Higgins NJ, Hill $A D$, Young LS: Expression of SRC-1, AIB1, and PEA3 in HER2 mediated endocrine resistant breast cancer; a predictive role for SRC-1. J Clin Pathol 2004, 57:1069-1074.

17. Girault I, Lerebours F, Amarir S, Tozlu S, Tubiana-Hulin M, Lidereau R, Bieche I: Expression analysis of estrogen receptor alpha coregulators in breast carcinoma: evidence that NCOR1 expression is predictive of the response to tamoxifen. Clin Cancer Res 2003, 9:1259-1266.

18. Hudelist G, Czerwenka K, Kubista E, Marton E, Pischinger K, Singer CF: Expression of sex steroid receptors and their co-factors in normal and malignant breast tissue: AIB1 is a carcinoma-specific co-activator. Breast Cancer Res Treat 2003, 78:193-204.

19. Myers E, Fleming FJ, Crotty TB, Kelly G, McDermott EW, O'Higgins NJ, Hill AD, Young LS: Inverse relationship between ER-beta and SRC-1 predicts outcome in endocrine-resistant breast cancer. Br J Cancer 2004, 91:1687-1693.

20. Zhao C, Yasui K, Lee CJ, Kurioka H, Hosokawa Y, Oka T, Inazawa J: Elevated expression levels of NCOA3, TOP1, and TFAP2C in breast tumors as predictors of poor prognosis. Cancer 2003, 98:18-23.

21. Karmakar S, Foster EA, Smith CL: Unique roles of $\mathrm{p} 160$ coactivators for regulation of breast cancer cell proliferation and estrogen receptoralpha transcriptional activity. Endocrinology 2009, 150:1588-1596.

22. McKenna NJ, O'Malley BW: Combinatorial control of gene expression by nuclear receptors and coregulators. Cell 2002, 108:465-474.

23. Yu ST, Reddy JK: Transcription coactivators for peroxisome proliferatoractivated receptors. Biochim Biophys Acta 2007, 1771:936-951.

24. Xu J, Li Q: Review of the in vivo functions of the p160 steroid receptor coactivator family. Mol Endocrinol 2003, 17:1681-1692.

25. Gojis O, Rudraraju B, Gudi M, Hogben K, Sousha S, Coombes RC, Cleator S, Palmieri C: The role of SRC-3 in human breast cancer. Nat Rev Clin Oncol 2010, 7:83-89.

26. Torres-Arzayus MI, Font de MJ, Yuan J, Vazquez F, Bronson R, Rue M, Sellers WR, Brown M: High tumor incidence and activation of the PI3K/AKT pathway in transgenic mice define AIB1 as an oncogene. Cancer Cell 2004, 6:263-274
27. Arimura A, vn Peer M, Schroder AJ, Rothman PB: The transcriptional coactivator p/CIP (NCoA-3) is up-regulated by STAT6 and serves as a positive regulator of transcriptional activation by STAT6. J Biol Chem 2004, 279:31105-31112.

28. Chen $H$, Lin RJ, Schiltz RL, Chakravarti D, Nash A, Nagy L, Privalsky ML, Nakatani Y, Evans RM: Nuclear receptor coactivator ACTR is a novel histone acetyltransferase and forms a multimeric activation complex with P/CAF and CBP/p300. Cell 1997, 90:569-580.

29. Louie MC, Zou JX, Rabinovich A, Chen HW: ACTR/AIB1 functions as an E2F1 coactivator to promote breast cancer cell proliferation and antiestrogen resistance. Mol Cell Biol 2004, 24:5157-5171.

30. Wu RC, Qin J, Yi P, Wong J, Tsai SY, Tsai MJ, O'Malley BW: Selective phosphorylations of the SRC-3/AIB1 coactivator integrate genomic reponses to multiple cellular signaling pathways. Mol Cell 2004, 15:937-949.

31. Azorsa DO, Cunliffe HE, Meltzer PS: Association of steroid receptor coactivator AIB1 with estrogen receptor-alpha in breast cancer cells. Breast Cancer Res Treat 2001, 70:89-101.

32. List HJ, Lauritsen KJ, Reiter R, Powers C, Wellstein A, Riegel AT: Ribozyme targeting demonstrates that the nuclear receptor coactivator AIB1 is a rate-limiting factor for estrogen-dependent growth of human MCF-7 breast cancer cells. J Biol Chem 2001, 276:23763-23768.

33. Tien JCY, Xu JM: Steroid receptor coactivator-3 as a potential molecular target for cancer therapy. Expert Opin Ther Targets 2012, 16:1085-1096.

34. Yan J, Erdem H, Li R, Cai Y, Ayala G, Ittmann M, Yu-Lee LY, Tsai SY, Tsai MJ: Steroid receptor coactivator-3/AIB1 promotes cell migration and invasiveness through focal adhesion turnover and matrix metalloproteinase expression. Cancer Res 2008, 68:5460-5468.

35. Planas-Silva MD, Shang Y, Donaher JL, Brown M, Weinberg RA: AIB1 enhances estrogen-dependent induction of cyclin D1 expression. Cancer Res 2001, 61:3858-3862.

36. Lahusen T, Henke RT, Kagan BL, Wellstein A, Riegel AT: The role and regulation of the nuclear receptor co-activator $\mathrm{AIB} 1$ in breast cancer. Breast Cancer Res Treat 2009, 116:225-237.

37. Yuan H, Lu J, Xiao J, Upadhyay G, Umans R, Kallkury B, Yin Y, Fant M, Kopelovich L, Glazer R: Peroxisome proliferator-activated receptor delta (PPAR delta) induces estrogen receptor-positive mammary neoplasia through an inflammatory and metabolic phenotype linked to mTOR activation. Cancer Res 2013, 73:1-13.

38. Chen $Y$, Schlessinger $D$, Nagaraja R: T antigen transformation reveals Tp53/RB-dependent route to PLAC1 transcription activation in primary fibroblasts. Oncogenesis 2013, 2:e67.

39. Yi P, Xia W, Wu RC, Lonard DM, Hung MC, O'Malley BW: SRC-3 coactivator regulates cell resistance to cytotoxic stress via TRAF4-mediated p53 destabilization. Genes Dev 2013, 27:274-287.

doi:10.1186/1471-2407-13-570

Cite this article as: Wagner et al:: NCOA3 is a selective co-activator of estrogen receptor a-mediated transactivation of PLAC1 in MCF-7 breast cancer cells. BMC Cancer 2013 13:570.

\section{Submit your next manuscript to BioMed Central and take full advantage of:}

- Convenient online submission

- Thorough peer review

- No space constraints or color figure charges

- Immediate publication on acceptance

- Inclusion in PubMed, CAS, Scopus and Google Scholar

- Research which is freely available for redistribution 